\title{
Enhanced serum concentrations of transforming growth factor-betal in simple fatty liver: is it really benign?
} Giovanni Tarantino*1, Paolo Conca ${ }^{1}$, Antonio Riccio ${ }^{1}$, Marianna Tarantino ${ }^{2}$, Matteo N Di Minno1, Domenico Chianese ${ }^{3}$, Fabrizio Pasanisi1, Franco Contaldo ${ }^{1}$, Francesco Scopacasa ${ }^{3}$ and Domenico Capone ${ }^{4}$

\author{
Address: ${ }^{1}$ Federico II University Medical School of Naples, Department of Clinical and Experimental Medicine, Naples, Italy, ${ }^{2}$ Federico Il \\ University Medical School of Naples, Department of Biomorphological and Functional Sciences, Naples, Italy, ${ }^{3}$ Federico II University Medical \\ School of Naples, Department of Biochemistry and Medical Biotechnology, Naples, Italy and ${ }^{4}$ Federico II University Medical School of Naples, \\ Department of Neurosciences, Section of Clinical Pharmacology, Naples, Italy \\ Email: Giovanni Tarantino* - tarantin@unina.it; Paolo Conca - paolo.conca@unina.it; Antonio Riccio - riccio@unina.it; \\ Marianna Tarantino - tarantin@unina.it; Matteo N Di Minno - diminno@unina.it; Domenico Chianese - scopacasa@unina.it; \\ Fabrizio Pasanisi - pasanisi@unina.it; Franco Contaldo - contaldo@unina.it; Francesco Scopacasa - scopacasa@unina.it; \\ Domenico Capone-docapone@unina.it \\ * Corresponding author
}

Published: 27 November 2008

Journal of Translational Medicine 2008, 6:72 doi:10.1 186/1479-5876-6-72
Received: 23 September 2008

Accepted: 27 November 2008

This article is available from: http://www.translational-medicine.com/content/6/1/72

(C) 2008 Tarantino et al; licensee BioMed Central Ltd.

This is an Open Access article distributed under the terms of the Creative Commons Attribution License (http://creativecommons.org/licenses/by/2.0), which permits unrestricted use, distribution, and reproduction in any medium, provided the original work is properly cited.

\begin{abstract}
Background: Inside the spectrum of non-alcoholic fatty liver disease, simple fatty liver is generally thought of as being "non progressive", differently from non-alcoholic steatohepatitis, which increases in severity due to the presence of apoptosis/inflammation and fibrosis. The "benignity" of fatty liver is widely accepted but conceptually difficult to maintain because the mechanisms underlying this entity are the same ones that determine the more severe form.

Findings provide evidence that iron overload is associated with increased liver damage and collagen deposition. Transforming growth factor-betal released by hepatic stellate cells during chronic liver injury plays a critical role in liver apoptosis and fibrogenesis.
\end{abstract}

Objective: To verify whether both the forms of non-alcoholic fatty liver disease were really dissimilar, evaluating the serum profile of two key parameters, indexes of severity.

Methods: A total of 123 patients ( 57 females) participated, forming three groups: forty five patients with fatty liver, 42 patients with non-alcoholic steatohepatitis and 36 with chronic hepatitis C. All had a biopsy-proven diagnosis.

Measurements: Serum concentrations of transforming growth factor-betal and ferritin.

Results: High concentrations of transforming growth factor-beta I were noticed in patients suffering from both fatty liver and non-alcoholic steatohepatitis, I29.I (45.4) versus II6.8 (42.2) ng/mL, $\mathrm{P}=0.2$; they were significantly superior to those of chronic hepatitis $C$ patients $87.5(39.5) \mathrm{ng} / \mathrm{mL}, \mathrm{P}<0.00$ I. Ferritin levels were on average above normal values and similar in the three groups $(P=0.9)$, also when adjusted for gender $(P=0.5)$ and age $(P=0.3)$.

Conclusion: No difference between serum concentrations of transforming growth factor-betal and ferritin in fatty liver and non-alcoholic steatohepatitis suggests that these forms share more common aspects, regarding their progression, than previously thought. 


\section{Background}

Non-alcoholic fatty liver disease (NAFLD) represents a complex of liver diseases that range from simple fatty liver (FL), at the most clinically benign end of the spectrum, through an intermediate, generally progressive lesion, non-alcoholic steatohepatitis (NASH) to cirrhosis, at the opposite end. Diagnosis of NAFLD can usually be done by imaging studies in absence of other liver disease. Liver biopsy is required to size disease severity (inflammation, degenerative lesion and fibrosis), even though some limitations cast doubts on its use in clinical settings [1].

The definition of "benignity" concerning FL is wideaccepted [2] but conceptually difficult to maintain because the mechanisms, i.e., insulin resistance (IR), underlying this entity are the same ones that determine the more severe form.

The key process in the progression of NAFLD from the very beginning to the end is fibrosis. An animal model of "fibrosing steatohepatitis" that replicates the histologic features of human NASH stresses the sequence of steatosis, inflammatory cell injury and fibrogenesis, mediated by hepatic stellate cells (HSCs) via up-regulation of transforming growth factor-beta1 (TGF- $\beta 1$ ) [3]. An alternative pattern is followed by leptin that facilitates proliferation and prevents apoptosis of HSCs [4].

There is an increasing body of evidence that iron overload is associated with metabolic syndrome (MS) and NAFLD [5]. Observation of liver fibrosis in a rat model of NASH suggests that iron induces increase in hepatocytes apoptosis and contributes to the development of fibrosis directly or indirectly via induction of TGF- $\beta 1$ production in hepatocytes and macrophages at an earlier time than expected [6]. It is important to stress that hepatocyte apoptosis is significantly increased in patients with NASH and correlates with disease severity [7].

TGF- $\beta 1$ is a profibrotic cytokine whose action is mediated by Smad proteins and p38 MAPK. They have been found to independently and additively regulate $\alpha 1$ (I) collagen gene expression by transcriptional activation, while p38 MAPK, but not Smad signaling, increases $\alpha 1(\mathrm{I})$ collagen mRNA stability leading to increased synthesis and deposition of type I collagen [8].

As previously reported, histology, which has not probably an optimal sensitivity and specificity, leads to biased accuracy estimates and gives a frozen-in-time picture. An approach to look into the supposed "benignity" of FL and "progressivity" of NASH is to speculate about eventual differences/similarities in mechanisms between the two entities. With this in mind, we tracked in a NAFLD cohort the behaviour of serum TGF- $\beta 1$, an indirect severity progres- sion index, and ferritin, an ancillary marker for IR, correlating their concentrations to those present in chronic hepatitis $\mathrm{C}$ (CHC), disease characterized by the combination of apoptosis/inflammation and fibrosis, in which TGF- $\beta 1$ and iron overload could play a key role too $[9,10]$.

\section{Methods \\ Population}

One hundred and forty six adult Caucasian patients from the beginning of 2005 to the end of 2007 were consecutively investigated at our Department (Figure 1) in a crosssectional fashion.

Every patient gave his or her informed consent to this study, which had been approved by the local Ethics Committee.

\section{NAFLD patients}

We enrolled 108 patients who fulfilled the following inclusion criteria: presence of overweight/obesity and visceral adiposity, associated with recent US features of "bright liver", with or without aminotransferases increase of unknown origin.

Subjects were classified as being overweight or as having first degree obesity on the basis of body mass index (BMI) cut-off points of $\geq 25.0$ and $\leq 29.9$, or $>29.9$ and $\geq 34.9$ $\mathrm{kg} / \mathrm{m}^{2}$, respectively. Central obesity was identified by waist circumference (WC) $>102 \mathrm{~cm}$ in men or $>88 \mathrm{~cm}$ in women, measured at the midpoint between the lower border of the rib cage and the iliac crest. Metabolic syndrome (MS) was defined according to the revised Adults Treatment Panel III (2001), and three or more criteria were considered: plasma glucose concentration of at least $100 \mathrm{mg} \mathrm{dL}^{-1}$, WC $>102 \mathrm{~cm}$ in men and $>88 \mathrm{~cm}$ in women, serum high-density lipoprotein (HDL)-cholesterol concentration $<40 \mathrm{mg} \mathrm{dL}^{-1}$ in men and $<50 \mathrm{mg} \mathrm{dL}^{-1}$ in women, blood pressure of at least $130 / 85 \mathrm{~mm} \mathrm{Hg}^{-1}$ and serum triglyceride concentration of at least $150 \mathrm{mg} \mathrm{dL}^{-1}$.

IR was calculated by modified homeostasis model assessment-index (HOMA), with the following formula: fasting insulin $(\mu \mathrm{U} / \mathrm{mL}) *$ plasma glucose $(\mathrm{mg} / \mathrm{dL}) / 405$ [11].

Exclusion criteria were a recent history of acute inflammation (very high, $\geq 4$ times the upper limit of normality, values of $C$ reactive protein, $C R P$ ); presence of hepatitis $B$ and $\mathrm{C}$, neoplastic and/or haematological diseases, autoimmune and storage diseases; prior (at least 3 months) use of drugs inducing hepatic steatosis or affecting inflammation or angiotensin-converting enzyme inhibitors/angiotensin II type 1 receptor blockers. Alcohol abuse was ruled out according to the DSM-IV diagnostic criteria, by means of screening tests such as MAST (Michigan Alcohol Screening Test) and CAGE (Cut down, 
146 subjects fully investigated

108 patients with NAFLD

87 out of 108 agreed to undergo it

forming two groups

\section{8 patients with $\mathrm{CHC}$}

\section{VER BI OPSY}

36 out of 38 agreed to undergo it

forming the control group
45 patients with FL 42 patients with NASH
36 patients with $\mathrm{CHC}$

\section{Figure I}

The flow of participants through the study. NAFLD, non-alcoholic fatty liver disease; FL, fatty liver; NASH, non-alcoholic steatohepatitis; $\mathrm{CHC}$, chronic hepatitis C.

Annoyed, Guilty, and Eye opener) [12], as well as random tests for blood alcohol concentration and the use of a surrogate marker, e.g., mean corpuscular volume. Patients on antihypertensive therapy maintained a balanced medical regimen throughout the study.

Eighty-seven out of 108 patients initially selected agreed to perform liver biopsy. On the basis of the results of hepatic histology, 42 patients ( 19 females) were assigned to the NASH group and 45 ( 21 females) to the FL one. Steatohepatitis was graded on the basis of the degree of macrovesicular steatosis, mixed lobular inflammation and hepatocyte ballooning, using a composite NAFLD activity score (NASH, > 5) [13]. The presence of perisinusoidal fibrosis was noted and scored as none, rare, mild or moderate. Early fibrosis was distinguished from advanced fibrosis based on the presence of bridging fibrosis (score of 3 or more).

\section{Chronic hepatitis $\boldsymbol{C}$ patients}

Thirty-eight individuals were diagnosed as to have elevated values of serum alanine aminotransferase (ALT) for at least six months. These subjects possessed detectable serum HCV-RNA (COBAS AmpliScreen HCV Test, v2.0, with automated amplification and detection using polymerase chain reaction method on the COBAS AMPLICOR Analyzer, Roche; the lower detection limit was 200 $\mathrm{IU} / \mathrm{mL}$ ), before starting antiviral treatment. Thirty-six patients (17 females) underwent liver biopsy. Histological features were evaluated using the Ishak scoring system for inflammation and fibrosis [14]. In brief, inflammation was scored using four parameters (periportal or periseptal interface hepatitis, confluent necrosis, focal lytic necrosis and portal inflammation) to obtain a histological activity index (HAI, maximum score 18), and fibrosis was scored as $0-6$. The selected patients' tissue specimens were considered adequate for evaluation when at least four portal (or septal) areas were available for review and if they had length superior to $1.5 \mathrm{~cm}$.

\section{Ultra Sonography}

Determinations were made by two expert operators, blinded to each other, using an ultrasound (US) diagnostic system (ESAOTE, Genoa, Italy) with a 3.5-MHz convex probe. The classification of "bright liver" was based on the following scale of hyperechogenity: $0=$ absent, $1=$ light, 2 = moderate, 3 = severe.

\section{Analytes}

CRP was dosed by an enzyme immunoassay kit of BioCheck, Inc, Foster City, CA, USA.

TGF- $\beta 1$ was dosed by using Quantikine immunoassay kit from R\&D Systems, Inc. Minneapolis, MN, USA. Serum separator tubes were used to allow samples to clot for 30 minutes at room temperature. For complete release of 
TGF- $\beta 1$, samples were incubated overnight at $2-8^{\circ} \mathrm{C}$ before centrifugation for 15 minutes at $1000 \times \mathrm{g}$. Removed serum was stored at $-70^{\circ} \mathrm{C}$.

The intra-assay and inter-assay precision coefficient variation was $3.4 \%$ and $8.4 \%$, respectively. TGF- $\beta 1$ levels in 15 controls showed a median of $26.9 \mathrm{ng} / \mathrm{mL}$, and $5^{\text {th }}-95^{\text {th }}$ percentile 23.0 - 34.0. The mean minimum detectable was $4.87 \mathrm{pg} / \mathrm{mL}$.

For the determination of ferritin in serum was used the Ferritin ELISA Quantitation kit by GenWay Biotech, Inc. San Diego, CA 92121. The minimum detectable ferritin concentration by the assay was $5.0 \mathrm{ng} / \mathrm{mL}$. Normal values were in males $20-370 \mathrm{ng} / \mathrm{mL}$ and in females $10-150 \mathrm{ng} /$ $\mathrm{mL}$. The inter-assay coefficients of variation were $4.2 \%$, $5.1 \%$ and $6.6 \%$ at the concentrations of 37,221 and 340 $\mathrm{ng} / \mathrm{mL}$, respectively, whereas the intra-assay coefficients of variation were $3.5 \%, 5.7 \%$ and $3.6 \%$ at the same concentrations, respectively.

Data collection of sonographic parameters was done before the histological classification, whereas serum ferritin and growth factor concentrations were obtained on stored samples.

The liver biopsy, blood samples and US parameters were strictly carried out within two months in order to lessen potentially confounding lifestyle changes or intercurrent illnesses.

\section{Statistics}

Variables normally distributed (Kolmogorov-Smirnov test) such as age $(P=0.13)$, ferritin $(P=0.12)$, ALT $(P=$ $0.1)$, CRP $(P=0.07)$ and TGF- $\beta 1(P=0.054)$ were expressed as mean (SD). BMI, not normally distributed ( $P$ $=0.003$ ), and ordinals, i.e., US and histology scores, were expressed as median and range.

The t test or ANOVA and the Mann-Withey test or KruskalWallis were adopted to compare means or median, respectively. The pairwise analysis of subgroups, post-hoc comparisons after ANOVA, was obtained by the Tukey test. Furthermore, the ANCOVA was used to control for factors. The chi square was performed to look for differences in the classification system. Tracking the degree of association between single parameters in each group, Pearson's $r$ or Spearman's rho was chosen according to the variable distribution (normal or not normal as well as being ordinals, respectively). Statistical analysis was performed operating on Systat 12 and MedCalc Version 9.4. software packages.

\section{Results}

The biopsy-proven selected population (Table 1) was well balanced for gender (Chi-square $=.03, \mathrm{P}=1$ ), and obviously not for BMI (Kruskal-Wallis, $\mathrm{P}=<0.001$ ). MS was indifferently represented across the NAFLD groups (20 out of 45 in FL and 25 out of 42 in NASH, Chi-square = 1.3, $\mathrm{P}=0.2)$.

In NAFLD patients we found high TGF- $\beta 1$ concentrations. No statistically significant difference was found between FL and NASH subgroups $(P=0.2)$.

Table I: Main laboratory data and characteristics of the studied population

\begin{tabular}{|c|c|c|c|c|c|c|c|c|c|}
\hline & \multicolumn{9}{|c|}{ Diagnosis } \\
\hline & \multicolumn{3}{|c|}{ CHC n 36} & \multicolumn{3}{|c|}{ FL n 45} & \multicolumn{3}{|c|}{ NASH n 42} \\
\hline & Gender & Mean & SD & Gender & Mean & SD & Gender & Mean & SD \\
\hline Age & & 44.5 & 10.0 & & 42.3 & 9.1 & & 40.4 & 10.5 \\
\hline TGF- $\beta \mathbf{I} \mathrm{ng} / \mathrm{mL}^{*}$ & & 87.5 & 39.5 & & 129.1 & 45.4 & & 116.8 & 42.2 \\
\hline CRP & & & & & 0.8 & 0.4 & & 0.9 & 0.4 \\
\hline ALT U/L\# & & 72.7 & 25.6 & & 49.2 & 17.8 & & 54.3 & 21.8 \\
\hline Ferritin $\mathrm{ng} / \mathrm{mL}$ & $17 \mathrm{~F}$ & 203.6 & 86.5 & $21 \mathrm{~F}$ & 232.3 & 117.4 & $19 \mathrm{~F}$ & 279.8 & 150.3 \\
\hline Ferritin $\mathrm{ng} / \mathrm{mL}$ & $19 M$ & 396.4 & 153.5 & $24 M$ & 381.5 & 137.2 & $23 M$ & 357.2 & 132.3 \\
\hline Waist Circumference $(\mathrm{cm})$ & & & & $21 \mathrm{~F}$ & 98 & 6.1 & $19 \mathrm{~F}$ & 100 & 4.7 \\
\hline Waist Circumference $(\mathrm{cm})$ & & & & $24 M$ & 105 & 6.3 & $23 M$ & 108 & 7.7 \\
\hline HOMA & & & & & 3.2 & 1.4 & & 3.4 & 1.5 \\
\hline & & Median & Range & & Median & Range & & Median & Range \\
\hline BMI & & 26 & $22-30$ & & 29 & $27-32$ & & 29 & $27-32$ \\
\hline Fibrosis score & & 1 & $1-3$ & & & & & 1 & $\mathrm{I}-2$ \\
\hline US steatosis Score & & 2 & $1-3$ & & & & & 1 & $1-3$ \\
\hline
\end{tabular}

$\mathrm{CHC}$, chronic hepatitis C; FL, fatty liver; NASH, non-alcoholic steatohepatitis; ALT, alanine aminotransferase; CRP, $\mathrm{C}$ reactive protein; TGF- $\beta$ I, transforming growth factor beta I; BMI, body mass index; HOMA, homeostasis model assessment-insulin resistance index.

$* \mathrm{P}<0.00 \mathrm{I}$, FL versus $\mathrm{CHC}$ and $0.008, \mathrm{NASH}$ versus $\mathrm{CHC}$ patients; $\# \mathrm{P}<0.00 \mathrm{I}, \mathrm{CHC}$ versus $\mathrm{FL}$ and $\mathrm{NASH}$ patients; $\ddagger \mathrm{P}<0.00 \mathrm{I}, \mathrm{CHC}$ versus $\mathrm{FL}$ and NASH patients. 
TGF- $\beta 1$ levels were more increased in FL and in NASH patients than CHC patients; this difference disappeared when data were adjusted for age.

Ferritin levels were found elevated and not different in the three groups $(\mathrm{P}=0.9)$, also when adjusted for gender $(\mathrm{P}=$ $0.5)$ and age $(P=0.3)$.

Serum TGF- $\beta 1$ was significantly correlated to serum ferritin considering the full population $(\mathrm{r}=0.23, \mathrm{P}=0.009$, Figure 2), especially in female patients $(\mathrm{r}=0.5, \mathrm{P}<0.001)$, in NASH female patients $(\mathrm{r}=0.45, \mathrm{P}=0.048)$ and in FL patients of both gender $(r=0.35, P=0.02)$, whereas in all the CHC patients there was only a certain trend $(r=0.32$, $\mathrm{P}=0.05)$. No association was found between CRP and TGF- $\beta 1(P=0.8)$. ALT activity showed a negative association with TGF- $\beta 1$ levels $(r=-0.34, P=0.026)$ in NASH patients and none in CHC patients $(P=0.9)$. Further details are shown in Table 2 and 3.

An inverse relationship was present between fibrosis score and serum TGF- $\beta 1$ (rho $=-0.27, \mathrm{P}<0.001)$.

High HOMA values were associated with high serum TGF$\beta 1$ levels $(\mathrm{r}=0.48, \mathrm{P}<0.001)$.

US steatosis score well correlated to $\mathrm{WC}$ in women (rho = $0.58, \mathrm{P}<0.001)$ as well as in men (rho $=0.61, \mathrm{P}<0.001)$.

\section{Discussion}

The key findings we provide are briefly i) subjects with FL and NASH exhibit quite the same elevated values of serum TGF- $\beta 1$, both greater than those present in CHC patients; ii) there is a fair correlation between levels of this cytokine and ferritin in FL patients.

Our data somehow disagree with the body of present knowledge. In fact, they provide evidence for the idea that, being fibrosis the key process that distinguishes the nonprogressive from the progressive form of NAFLD and having found a marker of fibrosis well represented in FL patients, FL should not be considered a benign disease yet. Further, we failed to confirm the crucial role of CRP in differentiating FL from NASH even though NASH patients revealed the highest concentrations [15].

Discussing possible mechanisms and explanations for our findings, we emphasize that TGF- $\beta 1$-induced fibrosis in organ pathology and dysfunction appears to be increasingly relevant to a variety of distinct diseases [16].

Enhanced serum TGF- $\beta 1$ concentrations could represent a marker of early activation of mesenchymal HSCs. This interpretation is strengthened by the findings of a negative correlation of serum TGF- $\beta 1$ with fibrosis score, feature of stable collagen deposition, and by a good correlation between the same cytokine and serum ferritin. In fact, liver iron deposits in $\mathrm{CHC}$ are common and associated with activation of HSCs, ultimately contributing to liver damage $[10,17]$.

Increasing evidence suggests hepatocyte apoptosis, due to increased oxidative stress, is a key mediator of liver injury in NAFLD [18]. But, is apoptosis restricted to hepatocytes alone? It is likely that, in an initial phase, apoptosis also acts on activated HSCs decreasing the collagen fibres [19]. This could happen in FL. Successively, this mechanism does not prevent the waterfall effect of hepatic fibrosis, characteristic feature of NASH. Alternatively, being the deposition and degradation of hepatic fibrous tissue a dynamic equilibrium course, increased expression patterns of matrix-metalloproteinases -1, -2, -3, and tissue inhibitors of metalloproteinases -1 and -2 genes could promotes the degradation of extra-cellular matrix in an early step, such as in FL. Anyway, the mechanisms remain to be further studied.

Although our results are referred to a larger population, we are not able to confirm that high levels of plasma TGF$\beta 1$ represent a possible method of diagnosing NASH in NAFLD patients [20].

We found that the criterion of liver enzymes increase, widely used to separate NASH from FL, is vanishing according to a recent study in which 25 out of 64 (39\%) patients with biopsy-proven FL was found to have ALT levels superior to $30 \mathrm{U} / \mathrm{L}$ [21]. In addition, having found no or negative correlation between ALT activity and TGF$\beta 1$ levels in NASH and $\mathrm{CHC}$ patients, respectively, suggests that TGF- $\beta 1$ is related to apoptosis rather than to inflammation.

Still, discussing other limitations, we should ask some questions.

Firstly, does a randomized determination mirror the "at steady state" serum concentration of this cytokine?

TGF- $\beta 1$ differs from the majority of growth regulatory factors since it is generally synthesized and secreted in a biologically latent form, and this must be activated before TGF- $\beta 1$ can exert its biological effects on target cells. TGF$\beta 1$ in this latent complex had a long plasma half-life (more than $100 \mathrm{~min}$ ). Having found elevated values of serum TGF- $\beta 1$ in FL, it is likely that a hepatic over-expression of the same cytokine is present. The only one serum determination for each patient is a "snapshot in time" methodology, but this is understandable; this alone with small numbers of patients in the 3 subgroups limits any definitive conclusion that can be drawn from this study. 
Table 2: Correlations between ferritin and other parameters

\begin{tabular}{|c|c|c|c|}
\hline & $\mathrm{CHC}$ & FL & NASH \\
\hline TGF- $\beta$ I & $\begin{array}{c}\text { Ferritin ( } 17 \text { females, } F) \\
\qquad \begin{array}{c}r=0.35 \\
P=0.16\end{array}\end{array}$ & $\begin{array}{c}\text { Ferritin }(2 \mathrm{I} F) \\
r=0.5 \\
P<0.001\end{array}$ & $\begin{array}{c}\text { Ferritin (19 F) } \\
r=0.46 \\
P=0.048\end{array}$ \\
\hline TGF- $\beta$ I & $\begin{array}{c}\text { Ferritin (19 males, M) } \\
\begin{aligned} r & =0.06 \\
P & =0.78\end{aligned}\end{array}$ & $\begin{array}{c}\text { Ferritin }(24 \mathrm{M}) \\
r=0.08 \\
P=0.8\end{array}$ & $\begin{array}{c}\text { Ferritin }(23 \mathrm{M}) \\
r=-0.26 \\
P=0.23\end{array}$ \\
\hline CRP & ND & $\begin{array}{l}\text { Ferritin }(F) \\
r=0.13 \\
P=0.57\end{array}$ & $\begin{array}{l}\text { Ferritin }(F) \\
r=0.36 \\
P=0.13\end{array}$ \\
\hline CRP & ND & $\begin{array}{l}\text { Ferritin }(M) \\
r=-0.49 \\
P=0.01\end{array}$ & $\begin{array}{c}\text { Ferritin }(M) \\
r=-0.08 \\
P=0.7\end{array}$ \\
\hline $\mathrm{ALT}$ & $\begin{array}{l}\text { Ferritin (females) } \\
\qquad \begin{array}{c}r=0.36 \\
P=0.18\end{array}\end{array}$ & $\begin{array}{c}\text { Ferritin }(F) \\
r=0.04 \\
P=0.85\end{array}$ & $\begin{array}{c}\text { Ferritin }(F) \\
r=-0.17 \\
P=0.48\end{array}$ \\
\hline $\mathrm{ALT}$ & $\begin{array}{l}\text { Ferritin }(M) \\
r=0.42 \\
P=0.07\end{array}$ & $\begin{array}{c}\text { Ferritin }(M) \\
r=-0.01 \\
P=0.95\end{array}$ & $\begin{array}{l}\text { Ferritin }(M) \\
r=0.42 \\
P=0.045\end{array}$ \\
\hline BMI & $\begin{array}{c}\text { Ferritin }(F) \\
\text { rho }=-0.13 \\
P=0.59\end{array}$ & $\begin{array}{c}\text { Ferritin }(F) \\
\text { rho }=-0.05 \\
P=0.8\end{array}$ & $\begin{array}{c}\text { Ferritin }(F) \\
\text { rho }=0.14 \\
P=0.5\end{array}$ \\
\hline BMI & $\begin{array}{c}\text { Ferritin }(M) \\
\text { rho }=-0.24 \\
P=0.3\end{array}$ & $\begin{array}{c}\text { Ferritin }(M) \\
\text { rho }=0.3 \\
P=0.14\end{array}$ & $\begin{array}{c}\text { Ferritin }(M) \\
\text { rho }=-0.22 \\
P=0.3\end{array}$ \\
\hline US score & ND & $\begin{array}{c}\text { Ferritin }(F) \\
\text { rho }=-0.19 \\
P=0.4\end{array}$ & $\begin{array}{c}\text { Ferritin }(F) \\
\text { rho }=-0.24 \\
P=0.31\end{array}$ \\
\hline US score & ND & $\begin{array}{l}\text { Ferritin }(M) \\
\text { rho }=-0.04 \\
P=0.85\end{array}$ & $\begin{array}{l}\text { Ferritin }(M) \\
\text { rho }=-0.24 \\
P=0.3\end{array}$ \\
\hline Fibrosis score & $\begin{array}{c}\text { Ferritin }(F) \\
\text { rho }=0.14 \\
P=0.37\end{array}$ & ND & $\begin{array}{c}\text { Ferritin }(F) \\
\text { rho }=-0.5 I \\
P=0.03\end{array}$ \\
\hline Fibrosis score & $\begin{array}{c}\text { Ferritin }(M) \\
\text { rho }=0.18 \\
P=0.44\end{array}$ & ND & $\begin{array}{c}\text { Ferritin }(M) \\
\text { rho }=0.20 \\
P=0.34\end{array}$ \\
\hline Age & $\begin{array}{c}\text { Ferritin }(F) \\
r=-077 \\
P=0.0003\end{array}$ & $\begin{array}{c}\text { Ferritin }(F) \\
r=-0.34 \\
P=0.13\end{array}$ & $\begin{array}{c}\text { Ferritin }(F) \\
r=-0.01 \\
P=0.68\end{array}$ \\
\hline Age & $\begin{array}{l}\text { Ferritin }(M) \\
r=0.40 \\
P=0.08\end{array}$ & $\begin{array}{l}\text { Ferritin }(M) \\
r=0.29 \\
P=0.16\end{array}$ & $\begin{array}{l}\text { Ferritin }(M) \\
r=-0.26 \\
P=0.23\end{array}$ \\
\hline
\end{tabular}

CHC, chronic hepatitis C; FL, fatty liver; NASH, non-alcoholic steatohepatitis; ALT, alanine aminotransferase; CRP, C reactive protein; TGF- $\beta$ I, transforming growth factor betal; BMI, body mass index; US score, hepatic steatosis score at ultrasound; $r$, Pearson's correlation coefficient and rho, Spearman's rank correlation coefficient, chosen according to the variable distribution (normal or not normal as well as being ordinals, respectively); ND, not determined; $F$, females; $M$, males. 
Secondly, why are not evident histological features of fibrosis in FL patients undergone liver biopsy?

Our findings do not represent an isolate case. In fact, HSC activation was not correlated to HAI and fibrosis score, valued by Knodell and Batts separate systems, in a subset of patients who developed severe hepatitis $C$ recurrence on 4-month after liver transplantation [22]. The interpretation could be that we similarly faced an early fibrogenesis that would have been apparent across a long period of time, making the TGF- $\beta 1$, indirect marker of HSC activation, better useful in predicting the subsequent hepatic fibrosis.

We could have carried out other markers of fibrosis for the noninvasively staging of NAFLD patients [23]. However, to date, none of these markers have been independently validated in different populations in a prospective way. Moreover, all of these studies have been tested in a crosssectional fashion, and then the role of these biomarkers for monitoring disease progression remains completely unknown.

Table 3: Correlations between TGF- $\beta$ I and other parameters

\begin{tabular}{|c|c|c|c|}
\hline & $\mathrm{CHCN}=36$ & FL $N=45$ & NASH N $=42$ \\
\hline \multirow[t]{3}{*}{ CRP } & ND & TGF- $\beta$ I & TGF- $\beta$ I \\
\hline & & $r=0.37$ & $r=0.29$ \\
\hline & & $P=0.08$ & $P=0.055$ \\
\hline \multirow[t]{3}{*}{$\mathrm{ALT}$} & TGF- $\beta$ I & TGF- $\beta$ I & TGF- $\beta$ I \\
\hline & $r=-0.02$ & $r=-0.13$ & $r=-0.34$ \\
\hline & $P=0.9$ & $P=0.38$ & $P=0.026$ \\
\hline \multirow[t]{3}{*}{ BMI } & TGF- $\beta$ I & TGF- $\beta$ I & TGF- $\beta$ I \\
\hline & rho $=0.13$ & rho $=0.18$ & rho $=0.09$ \\
\hline & $P=0.46$ & $P=0.22$ & $P=0.56$ \\
\hline \multirow[t]{3}{*}{ US score } & ND & TGF- $\beta$ I & TGF- $\beta$ I \\
\hline & & rho $=-0.08$ & rho $=0.05$ \\
\hline & & $P=0.57$ & $P=0.72$ \\
\hline \multirow[t]{3}{*}{ Fibrosis score } & TGF- $\beta$ I & ND & TGF- $\beta$ I \\
\hline & rho $=-0.09$ & & rho $=0.05$ \\
\hline & $P=0.60$ & & $P=0.75$ \\
\hline \multirow[t]{3}{*}{ Age } & TGF- $\beta$ I & TGF- $\beta$ I & TGF- $\beta$ I \\
\hline & $r=-0.02$ & $r=0.02$ & $r=-0.009$ \\
\hline & $P=0.9$ & $P=0.9$ & $P=0.9$ \\
\hline
\end{tabular}

$\mathrm{CHC}$, chronic hepatitis C; FL, fatty liver; NASH, non-alcoholic steatohepatitis; ALT, alanine aminotransferase; CRP, $C$ reactive protein; TGF- $\beta$ I, transforming growth factor beta I; BMI, body mass index; US score, hepatic steatosis score at ultrasound; $r$, Pearson's correlation coefficient and rho, Spearman's rank correlation coefficient, chosen according to the variable distribution (normal or not normal as well as being ordinals, respectively); ND, not determined.

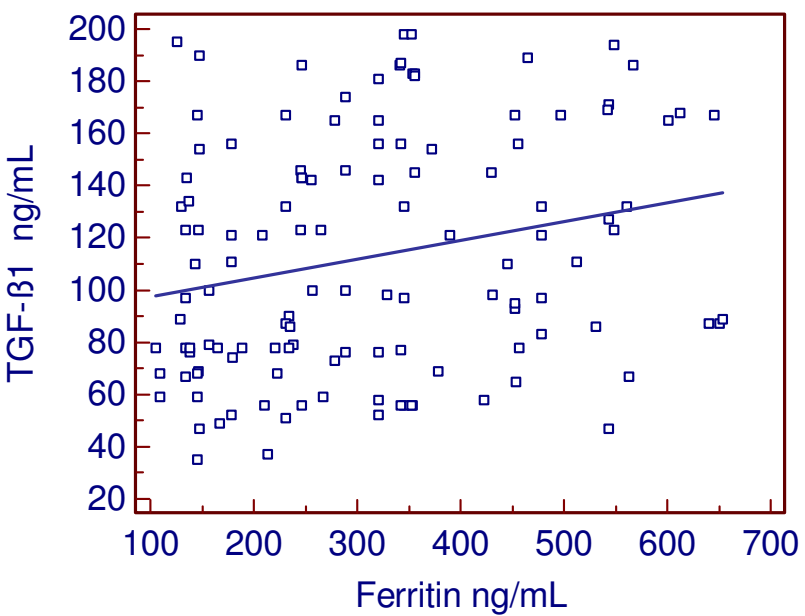

Figure 2

Association between serum TGF- $\beta I$ and ferritin.

TGF- $\beta$ I, transforming growth factor-betal.

To let us get down to the grassroots of the FL benignity from the beginning we should relay on longitudinal observations lasting several years, but this approach is difficult to plan. Crucial future research directions could be assessing liver fibrosis in FL patients during a long period of time by using non invasive tools such as fibrosis markers or elastograghy.

\section{Conclusion}

Similar levels of TF $\beta 1$ and ferritin in fatty liver and nonalcoholic steatohepatitis suggest that these forms share some common aspects, regarding their progression. If FL can evolve in liver cirrhosis, factors underlying this illness should be more intensively corrected, representing NAFLD also an epiphenomenon of MS, which has become a major health problem.

\section{Abbreviations}

(NAFLD): Non-alcoholic fatty liver disease; (FL): fatty liver; (NASH): non-alcoholic steatohepatitis; (IR): insulin resistance; (CHC): chronic hepatitis C; (TGF- $\beta 1)$ : transforming growth factor-beta1; (HSCs): hepatic stellate cells; (MS): metabolic syndrome; (BMI): body mass index; (CRP): C reactive protein; (WC): waist circumference; (HOMA): homeostasis model assessment-index; (MAST): Michigan alcohol screening test; (CAGE): cut down, annoyed, guilty, eye opener; (ALT): alanine aminotransferase.

\section{Competing interests}

The authors declare that they have no competing interests.

\section{Authors' contributions}

FS and DCa carried out the laboratory analyses. MT performed the ultrasound studies. DCh, MND, PC, FP, AR 
and FC participated in the design of the study and in drafting the manuscript. GT conceived of the research, was the main investigator and the coordinator of the study, made the statistics and drafted the manuscript. All authors read and approved the final manuscript.

\section{References}

I. de Oliveira CP, de Mello ES, Alves VA, Saviero SM, Strauss E: Changes in histological criteria lead to different prevalences of nonalcoholic steatohepatitis in severe obesity. Ann Hepatol 2007, 6:255-61.

2. Adams LA, Lymp JF, St Sauver J, Sanderson SO, Lindor KD, Feldstein $A$, Angulo $P$ : The natural history of nonalcoholic fatty liver disease: a population-based cohort study. Gastroenterology 2005, 129: | |3-2|.

3. George J, Pera N, Phung N, Leclercq I, Yun Hou J, Farrell G: Lipid peroxidation, stellate cell activation and hepatic fibrogenesis in a rat model of chronic steatohepatitis. J Hepatol 2003, 39:756-64.

4. Qamar A, Sheikh SZ, Masud A, Jhandier MN, Inayat IB, Hakim W, Mehal WZ: In vitro and in vivo protection of stellate cells from apoptosis by leptin. Dig Dis Sci 2006, 5 I: 1697-705.

5. Zelber-Sagi S, Nitzan-Kaluski D, Halpern Z, Oren R: NAFLD and hyperinsulinemia are major determinants of serum ferritin levels. J Hepatol 2007, 46:700-7.

6. Imeryuz N, Tahan V, Sonsuz A, Eren F, Uraz S, Yuksel M, Akpulat S, Ozcelik D, Haklar G, Celikel C, Avsar E, Tozun N: Iron preloading aggravates nutritional steatohepatitis in rats by increasing apoptotic cell death. J Hepatol 2007, 47:85I-9.

7. Feldstein $A E$, Canbay A, Angulo P, Taniai M, Burgart LJ, Lindor KD, Gores GJ: Hepatocyte apoptosis and fas expression are prominent features of human nonalcoholic steatohepatitis. Gastroenterology 2003, I 25:437-443.

8. Tsukada S, Westwick JK, Ikejima K, Sato N, Rippe RA: Smad and p38 MAPK signaling pathways independently regulate $\alpha I(I)$ collagen gene expression in unstimulated and TGF- $\beta$ stimulated hepatic stellate cells. J Biol Chem 2005, 280:10055-64.

9. Kanzler S, Baumann M, Schirmacher P, Dries V, Bayer E, Gerken G, Dienes HP, Lohse AW: Prediction of progressive liver fibrosis in hepatitis $C$ infection by serum and tissue levels of transforming growth factor-beta. J Viral Hepat 200I, 8:430-7.

10. Sumida Y, Kanemasa K, Fukumoto K, Yoshida N, Sakai K: Hepatic iron accumulation may be associated with insulin resistance in patients with chronic hepatitis C. Hepatol Res 2007, 37:932-40.

II. Matthews DR, Hosker JP, Rudenski AS, Naylor BA, Treacher DF, Turner RC: Homeostasis model assessment: insulin resistance and beta-cell function from fasting plasma glucose and insulin concentrations in man. Diabetologia 1985, 28:412-9.

12. Forsberg L, Halldin J, Ekman S, Rönnberg S: Screening of binge drinking among patients on an emergency surgical ward. Alcohol 2002, 27:77-82.

13. Kleiner DE, Brunt EM, Van Natta M, Behling C, Contos MJ, Cummings OW, Ferrell LD, Liu YC, Torbenson MS, Unalp-Arida A, Yeh M, McCullough AJ, Sanyal AJ, Nonalcoholic Steatohepatitis Clinical Research Network: Nonalcoholic Steatohepatitis Clinical Research Network Design and validation of a histological scoring system for nonalcoholic fatty liver disease. Hepatology 2005, 4|:|3|3-2|.

14. Ishak K, Baptista A, Bianchi L, Callea F, De Groote J, Gudat F, Denk $\mathrm{H}$, Desmet V, Korb G, MacSween RN, et al:: Histological grading and staging of chronic hepatitis. J Hepatol 1995, 22:696-9.

15. Yoneda M, Mawatari H, Fujita K, lida H, Yonemitsu K, Kato S, Takahashi H, Kirikoshi H, Inamori M, Nozaki Y, Abe Y, Kubota K, Saito S, Iwasaki T, Terauchi Y, Togo S, Maeyama S, Nakajima A: High-sensitivity C-reactive protein is an independent clinical feature of nonalcoholic steatohepatitis (NASH) and also of the severity of fibrosis in NASH. J Gastroenterol 2007, 42:573-82.

16. Khan R, Sheppard R: Fibrosis in heart disease: understanding

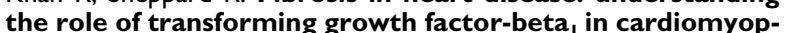
athy, valvular disease and arrhythmia. Immunology 2006, I 18:10-24.
17. Martinelli AL, Ramalho $\mathrm{LN}$, Zucoloto S: Hepatic stellate cells in hepatitis $C$ patients: relationship with liver iron deposits and severity of liver disease. J Gastroenterol Hepatol 2004, 19:91-8.

18. Ribeiro PS, Cortez-Pinto H, Solá S, Castro RE, Ramalho RM, Baptista A, Moura MC, Camilo ME, Rodrigues CM: Hepatocyte apoptosis, expression of death receptors, and activation of NF-kappaB in the liver of nonalcoholic and alcoholic steatohepatitis patients. Am J Gastroenterol 2004, 99: 1708-17.

19. Langer DA, Das A, Semela D, Kang-Decker N, Hendrickson H, Bronk SF, Katusic ZS, Gores G], Shah VH: Nitric oxide promotes caspase-independent hepatic stellate cell apoptosis through the generation of reactive oxygen species. Hepatology 2008, 47:1983-93

20. Hasegawa T, Yoneda M, Nakamura K, Makino I, Terano A: Plasma transforming growth factor-betal level and efficacy of alphatocopherol in patients with non-alcoholic steatohepatitis: a pilot study. Aliment Pharmacol Ther 200I, I 5:1667-72.

21. Kunde SS, Lazenby AJ, Clements RH, Abrams GA: Spectrum of NAFLD and diagnostic implications of the proposed new normal range for serum ALT in obese women. Hepatology 2005, 42:650-6.

22. Gawrieh S, Papouchado BG, Burgart LJ, Kobayashi S, Charlton MR, Gores G]: Early hepatic stellate cell activation predicts severe hepatitis $\mathbf{C}$ recurrence after liver transplantation. Liver Transpl 2005, I I:I207-13.

23. Palekar NA, Naus R, Larson SP, Ward J, Harrison SA: Clinical model for distinguishing nonalcoholic steatohepatitis from simple steatosis in patients with nonalcoholic fatty liver disease. Liver Int 2006, 26:15I-6.
Publish with BioMed Central and every scientist can read your work free of charge

"BioMed Central will be the most significant development for disseminating the results of biomedical research in our lifetime. "

Sir Paul Nurse, Cancer Research UK

Your research papers will be:

- available free of charge to the entire biomedical community

- peer reviewed and published immediately upon acceptance

- cited in PubMed and archived on PubMed Central

- yours - you keep the copyright

Submit your manuscript here:

http://www.biomedcentral.com/info/publishing_adv.asp
BioMedcentral 